Military Technical College Kobry EI-Kobbah, Cairo, Egypt.

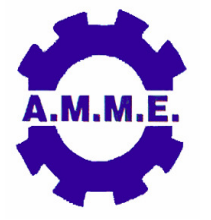

\title{
MODELING OF METALLIZED SOLID FUEL HYBRID PROPULSION SYSTEM
}

\author{
A. E. Makled ${ }^{*}$ H. E. Mostafa*, M. A. Al-Sanabawy ${ }^{\star}$ and M. J. Al-Timimi**
}

\begin{abstract}
The most commonly used Hybrid Rocket Motor (HRM) consists of an inert pure solid fuel (SF) with liquid or gaseous oxidizer. Until now, the regression rate of SF in HRM has typically been an order of magnitude lower than that of solid propellant motor. The objective of this paper is to investigate the possible enhancement of regression rate by addition of metal powder. This may guide to effectively design and produce high performance HRM for specific applications.
\end{abstract}

A mathematical model has been introduced and a computer program is built to describe metalized SF regression rate and HRM performance. A series of experimental tests using a small scale HRM employs Polyethylene (PE) with Aluminum (Al) metal powder additive $(2.5,5,7.5,10,12.5$, and $15 \%$ by mass) as SF and gaseous oxygen (GO2) as oxidizer to evaluate the metalized SF regression rate and HRM performance.

The measured experimental data are compared with results obtained from theoretical computation. The comparison shows good agreement, which proves the validity of the developed program, since the maximum error noticed was generally less than $10 \%$. An addition of up to $7.5 \% \mathrm{Al}$ powder increases the regression rate by about $90 \%$ and the chamber pressure by nearly $40 \%$ as compared to classical HRM with no additives.

\section{KEY WORDS}

Hybrid Rocket Motor performance, Regression rate, metal powder additive.

\footnotetext{
* Egyptian Armed Forces.

** Bahrain Armed Forces.
} 


\section{INTRODUCTION}

The chemical propulsion systems are used to provide energy from chemical reactions between the propellant components (oxidizer and fuel). The overall efficiency and performance parameters of the chemical propulsion (liquid (LPS), solid (SPS), hybrid propellant propulsion systems (HPS) and ramjet, (RJS)) depend largely on the choice of fuel and oxidizer propellants. The HRS is a type of chemical propulsion system, which employs propellant ingredients separated both physically and by phase. This separation is the major source of safety.

The fluid dynamic and combustion processes in the HRM are characterized by complex interactions between numerous physical phenomena, taking place simultaneously in the combustion chamber. These complex interactions can include solid-fuel pyrolysis, oxidizer atomization and vaporization, gas-phase diffusion, mixing, reaction and combustion, turbulent flow with mass addition, convective and radiative heat transfer, and varying SF grain port configuration. The SF regression rate, which is a very important design and performance parameter, is strongly affected by the operating conditions and/or the propellant combination and ingredient.

In the typical classical HPS, the fuel is solid and the oxidizer is liquid or gas state. Although there are many components that are common to the liquid and the solid propulsion systems, the combustion operation of a hybrid system is distinctly different. In the solid rocket, the oxidizer and the fuel are intimately mixed in the single solid phase and combustion occurs when the exposed surface is heated by the combustion flame to the ignition temperature. In the liquid rocket, both oxidizer and fuel are intimately mixed in the vicinity of the injector to form a combustible mixture. The hybrid propellant is burnt in a turbulent diffusion flame zone, where the oxidizer-to-fuel ratios (O/F) approximately close to stochiometric and varies down the length of the chamber. Therefore, the hybrid combustion process in a HPS differs very essentially from that of a solid or liquid rocket. The regression rate behavior depends on the heat transfer phenomena, oxidizer mass flow rate and grain port geometry.

The effects of adding energetic materials on the solid-fuel grain to enhance the regression rate are of much interest to the development of performance prediction like solid propellant. Therefore, these effects have been the subjects of many basic studies, which reached debatable conclusions among researchers in hybrid propulsion. It is safer to incorporate energetic additives in the SF grain because of the inherent inertness of the hybrid fuel regression rate.

\section{HYBRID PROPELLANT COMBUSTION AND REGRESSION RATE}

\section{Combustion Process in HPS}

During HRM combustion, the boundary layer is formed above the surface of the SF grain, as shown in Figure (1). This layer is fed by the oxidizer entering from the side of the channel axis and by gasified fuel entering from the other side. In the steady 
state, the oxidizer droplets are heated as they pass through the boundary layer these droplets tend to evaporate due to the existence of the flame zone with high temperature above the premixed reaction zone. Fuel is partially decomposed and evaporated (gasified) at the solid surface by convective (or convective and radiative) heat transfer and diffuses inward towards the centerline of the combustion volume. Simultaneously, gaseous oxidizer diffuses outward from the centerline through the turbulent boundary layer. At a point where the ratio of oxidizer to fuel (O/F ratio) concentration is somewhat at fuel-rich side of a stochiometric, combustion occurs in a layer whose thickness is of the order of $10 \%$ of the boundary layer thickness. The flame position is substantially closer to the SF surface than the edge of the boundary layer [1].

Due to the mechanism of the propellant combustion, the regression behavior of a HRM grain differs considerably from that of a solid rocket propellant. Hybrid combustion mechanism is internally tabulated burned grain, fuel is melted, decomposed and evaporated (gasified) at the solid surface by convective and radiative heat transfer.

The rate of regression rate is governed by the rate at which heat is transferred from the flame zone to the fuel surface rather than by grain configuration with chemical kinetics of the reaction. In a non-metallized fuel grain more simple than metal additives, heat transfer by convection is much larger than that transferred by gas phase radiation in non-metallized.

\section{Regression Rate Empirical Formulas}

The SF surface regression occurs in a direction normal to the burnt surface. A considerable number of expressions for the regression rate proposed by different authors are found. Some of these expressions are presented here to examine the different factors that govern the regression rate.

Humble and Altman [2] expressed the regression rate as:

$$
\dot{r}_{f u}=a G_{\text {tot }}^{n} L_{f u}^{m}
$$

where $\dot{r}_{f u}$ is the fuel regression rate, $L_{f u}$ is the fuel grain length and $G_{\text {tot }}$ is the sum of oxidizer and fuel fluxes. The constants $a, n$ and $m$ are characteristic of the propellant.

Waidmann [3] expressed the regression rate as:

$$
\dot{r}_{f u}=a P_{c}^{\alpha} G_{\text {tot }}^{n}\left(C_{t h}^{*}\right)^{q}
$$

where $\alpha, n$ and $\mathrm{q}$ are constants, $\mathrm{P}_{\mathrm{c}}$. combustion chamber pressure and $\mathrm{C}_{\text {th }}^{*}$ theoretical characteristic velocity.

Smoot and Price [1] proposed three different forms, according to the magnitude of the total mass flux: 


$$
\begin{array}{ll}
\dot{r}_{f u}=a G_{o x}^{0.8} & \text { for low flux value } \\
\dot{r}_{f u}=\frac{a b G_{o x}^{0.8} P_{c}^{n}}{a G_{o x}^{0.8}+b p_{c}^{n}} & \text { for medium flux value } \\
\dot{r}_{f u}=a p_{c}^{n} & \text { for high flux value }
\end{array}
$$

In the region of small oxidizer mass flux $\left(G_{o x}<10^{-1} \mathrm{~kg} \mathrm{~m}^{-2} \mathrm{~s}^{-1}\right)$ the $\dot{\mathrm{r}}_{\mathrm{fu}}$ is influenced by the heat transfer in the turbulent boundary layer. It does not depend on the $P_{c}$.

In the transient region of smaller $\mathrm{P}_{\mathrm{c}}$ and modest $\mathrm{G}_{\mathrm{ox}} \in\left(10 \sim 800 \mathrm{~kg} \mathrm{~m}^{-2} \mathrm{~s}^{-1}\right)$, the $\dot{\mathrm{r}}_{\mathrm{fu}}$ depends on both the oxidizer mass flux and the combustion pressure $P_{c}$.

In the region of higher oxidizer mass flux $\left(G_{o x}>800 \mathrm{~kg} \mathrm{~m}^{-2} \mathrm{~s}^{-1}\right)$, the $\dot{r}_{f u}$ is influenced by the $P_{c}$ and does not depend on $G_{o x}$.

The simplified formula for the regression rate is:

$$
\dot{r}_{\mathrm{fu}}=\mathrm{a} \mathrm{P}_{\mathrm{c}}^{\alpha} \mathrm{G}_{\mathrm{tot}}^{\mathrm{n}}
$$

If the mass flux of oxidizer is considered, the formula of regression rate becomes:

$$
\dot{r}_{f u}=a P_{c}^{a} G_{o x}^{n}
$$

The constants $\mathrm{a}, \mathrm{n}$ and $\alpha$ depend on the propellant.

The pressure sensitivity exponent $\alpha$ and the mass flow exponent $\mathrm{n}$ can be considered within certain limits as constants. The parameters $\mathrm{a}, \mathrm{n}$ and $\alpha$ are determined experimentally by measuring the regression rates at different values of $m_{o x}$ and $P_{C}$. The practical values in this expression are $\dot{r}_{f u} \in(1.3-5.1) \mathrm{mm} / \mathrm{s}, \mathrm{n} \in$ $(0.4-0.7)$ and $\alpha \in(0-0.25)$.

The mass flux exponent $\mathrm{n}$ is of a main interest, because it has significant effects on the operating conditions. In some cases, the pressure effect is negligible $(\alpha \sim 0)$ and therefore, equation (5) is simplified to:

$$
\dot{\mathrm{r}}_{\mathrm{fu}}=\mathrm{a} \mathrm{G}_{\mathrm{ox}}^{\mathrm{n}}
$$

In conclusion, the essential parameters, affecting the $\dot{r}_{f u}$ are the oxidizer mass flux, fuel grain port diameter and the $P_{c}$. It is also slightly affected by initial temperature of the fuel grain.

During the development and investigation of HRM, different methods to measure the regression rate have been used. An observation window located in a twodimensional HRM has been utilized for measurement. The regression rate measurement has been accomplished by means of optical methods [3, 4, and 5], 
acoustical methods [6], electrical probe [7], fuel grain loss, final port diameter measurements, and by chamber pressure shifting [3, 4, and 5].

\section{Modification of Regression Rate}

One of the disadvantages of HPS is their low regression rates, compared to SPS. To achieve higher regression rates, it is important to understand which determining factors are involved. Elementary considerations show that $\dot{r}_{f u}$ is determined by the quantity of heat transferred to the fuel surface relative to the heat needed for complete gasification of the fuel surface. Low values of the latent heats of melting and vaporization tend to increase the $\dot{r}_{f u}$. Also high temperature in the combustion zone (flame zone) enhance the $\dot{r}_{f u}$ at a short distance from the fuel surface.

Tagaform, a synthetic fuel that consists mainly of a polymer of an aromatic amine and a low-molecular weight, aldehyde is well suited for applications where high $\dot{r}_{\text {fu }}$ values are essential. $A \dot{r}_{f u}$ is 5 to 10 times higher than for the conventional fuel types (PMMA, PE, HTPB) can be attained with this fuel No additives have been used to achieve this higher rate, which may be the consequence of an unusually low heat of melting.

Approximately $1 \%$ by total fuel weight carbon black powder was mixed with PMMA to produce fuel grains opaque to thermal radiation. This resulted in increased $\dot{r}_{f u}$. Small amount of oxidizer in form of metal powder was mixed with hybrid SF, to increase the $\dot{r}_{f u}[1]$.

The trials to increase regression rates started in the 1960s when both $\mathrm{NH}_{4} \mathrm{ClO}_{4}$ [ammonium perchlorate (AP)] and $\mathrm{NH}_{4} \mathrm{NO}_{3}$ [ammonium nitrate (AN)] were employed as fuel additives. Various other energetic additives such as nitro organic compounds, RDX $\left(\mathrm{CH}_{2} \mathrm{~N}_{2} \mathrm{O}_{2}\right)_{3}$ and $\mathrm{HMX}\left(\mathrm{CH}_{2} \mathrm{~N}_{2} \mathrm{O}_{2}\right)_{4}$ have been added to conventional PB fuels to lower the heat of vaporization effectively by generating an exothermic reaction in the vicinity of the propellant surface. Although this approach is effective, its main deterrent is that manufacturing, handling, and shipping costs can be increased due to an increased hazard classification.

\section{SOLID-FUEL ADDITIVES SELECTION}

The criteria for selection of additives (metals) to be used with solid fuel are mainly, its heat of combustion, physical properties, high thermal conductivity, low specific heat, low latent heat of fusion, low density, and melting point suitable relative to the fuel surface temperature.

In the present work, AL metal particles additive found of great interest due to its inherent advantages such as damping of pressure oscillations and increase in regression rate $\dot{r}_{f u}$, chamber temperature $T_{c}$, molecular weight of combustion gases $M$, specific impulse $I_{s p}$ and propellant density $\rho_{p r}$. 
It is interesting, to investigate the theoretical limit of $I_{s p}$ for chemical propellants. Since $\mathrm{I}_{\mathrm{sp}}$ is proportional to $\sqrt{\mathrm{T}_{\mathrm{c}} / \mathrm{M}}$ one has to look for propellants giving a high combustion temperature and low average molecular weight for the combustion products.

Generally, adding metal particles to fuel grain material increases combustion temperature lading to enhance performance, However, the metal usually also increase the mean molecular weight of the combustion gases which tends to decrease performance. Therefore, only metals with a low molecular weight are usually applied.

For the polymer fuel material the following metals and solid oxidizer were considered as possible additives: Lithium (Li), Beryllium (Be), Boron (B), Magnesium (Mg), Aluminum $(A L)$, Ammonium Per-chlorate (AP), Ammonium nitrate (AN).

The influences of these metal additives were compared using thermo-chemical calculation [8]. Table (1) shows thermodynamic and physical properties of several energetic additives.

Table (1) Physical and thermodynamic properties of common energetic additives.

\begin{tabular}{|c|c|c|c|c|c|c|c|}
\hline \multirow{2}{*}{ Fuel } & \multicolumn{2}{|c|}{$\begin{array}{l}\text { Virgin material } \\
\text { properties }\end{array}$} & \multirow{2}{*}{$\begin{array}{l}\text { Gravimetric } \\
\text { heat of } \\
\text { oxidation } \\
\text { kJ/gm fuel }\end{array}$} & \multirow{2}{*}{$\begin{array}{c}\text { volumetric } \\
\text { heat of } \\
\text { oxidation } \\
\mathrm{kJ} / \mathrm{cm}^{3}\end{array}$} & \multirow{2}{*}{$\begin{array}{l}\text { Final } \\
\text { oxide }\end{array}$} & \multicolumn{2}{|c|}{$\begin{array}{l}\text { Final oxide } \\
\text { properties }\end{array}$} \\
\hline & $\begin{array}{c}\rho \\
\left(\mathrm{gm} / \mathrm{cm}^{3}\right)\end{array}$ & $\begin{array}{l}\mathbf{T}_{\text {melt }} \\
{ }^{\circ} \mathrm{C}\end{array}$ & & & & $\underset{\left(\mathrm{gm} / \mathrm{cm}^{3}\right)}{\rho}$ & $\mathrm{T}_{\text {melt }}{ }^{\circ} \mathrm{C}$ \\
\hline Aluminum $(\mathrm{Al})$ & 2.70 & 660 & 31.1 & 83.9 & $\mathrm{Al}_{2} \mathrm{O}_{3}(\mathrm{~s})$ & 3.97 & 2054 \\
\hline Boron (B) & 2.34 & 2077 & 58.7 & 137.0 & $\mathrm{~B}_{2} \mathrm{O}_{3}(\mathrm{~s})$ & 2.46 & 450 \\
\hline Beryllium (Be) & 1.85 & 1287 & 66.5 & 123.0 & $\mathrm{Be} \mathrm{O}(\mathrm{s})$ & 3.01 & 2530 \\
\hline Iron (Fe) & 7.86 & 1535 & 7.39 & 58.1 & $\mathrm{Fe}_{2} \mathrm{O}_{3}(\mathrm{~s})$ & 5.24 & 1462 \\
\hline Lithium (Li) & 0.534 & 181 & 43.2 & 23.0 & $\mathrm{Li}_{2} \mathrm{O}(\mathrm{s})$ & 2.013 & $\square 1700$ \\
\hline Magnesium (Mg) & 1.74 & 649 & 24.7 & 43.0 & $\mathrm{Mg} \mathrm{O} \mathrm{(s)}$ & 3.58 & 2832 \\
\hline Carbon (C) & 2.25 & 3652 & 32.8 & 73.8 & $\mathrm{CO}_{2}(\mathrm{~g})$ & 0.0019 & -56.6 \\
\hline Silicon (Si) & 2.33 & 1412 & 32.3 & 75.2 & $\mathrm{SiO}_{2}(\mathrm{~s})$ & 2.20 & 1723 \\
\hline Tungsten (W) & 19.35 & 3407 & 4.59 & 88.8 & $\mathrm{WO}_{3}(\mathrm{~s})$ & 7.16 & 1473 \\
\hline
\end{tabular}

Aluminum seems to be the best choice based on its thermal properties, ease of processing, and relatively low cost. However, the existence of $\mathrm{Al}_{2} \mathrm{O}_{3}$ as an inert oxide layer on the external surface of the particle is undesirable and hard to avoid. The amount of active aluminum in the particle depends on the manufacturing process and storage conditions. The sizes of these particles about micrometers, with the smallest are being 2-5 $\mu \mathrm{m}$. There are many direct advantages for incorporating nanosized particles into solid fuels and fuel-rich propellants such as:

1) Shorter ignition delay.

2) Shorter burning time based on the consideration of the $d^{2}$ law.

3) More complete combustion in volume-limited propulsion systems.

4) Higher particle specific surface area enhancing the rate of heat transfer.

5) Greater flexibility in designing new energetic fuels with desirable physical properties. 


\section{ALUMINUM-BASED PARTICLE ADDITIVES IN SOLID FUELS}

Many researchers have considered the addition of Al to both traditional polymeric binders and recently to PE materials. The main advantages of $\mathrm{Al}$ are the relatively high heat of oxidation $(31.1 \mathrm{~kJ} / \mathrm{gm})$, relatively high density $\left(2.7 \mathrm{~g} / \mathrm{cm}^{3}\right)$, and ease of ignition in the hot combustion environment of the rocket motor chamber. These properties make Al an attractive additive for increasing the performance of a propulsion system, especially a volume-limited system.

In the mid-1960s. United Technology Corporation (UTC) of Sunnyvale, California investigated the application of a prepackaged hybrid-propulsion system for application to tactical missile systems for the U.S. Air Force the final fuel selections for application and further evaluation contained $20 \%$ Al powder with polymer as a fuel, eight tests were conducted with Al [10]. The mechanism of Al particle combustion is shown in Figure (2).

Aluminum oxide formation when the oxidizer is oxygen and the product of oxygen with hydrocarbon material $(\mathrm{PE})$ are $\mathrm{CO}_{2}$ and $\mathrm{H}_{2} \mathrm{O}$.

$$
\begin{gathered}
\mathrm{Al}_{(\mathrm{s})} \stackrel{\text { flame zone heat radition }}{\mathrm{Al}(\mathrm{L}) \stackrel{\text { Combustion }}{\longrightarrow} \mathrm{Al}_{(\mathrm{g})}} \\
\mathrm{Al}_{(\mathrm{g})}+\mathrm{O}_{2} \longrightarrow \mathrm{AlO}_{(\mathrm{g})}+\mathrm{O} \\
2 \mathrm{AlO}_{(\mathrm{g})}+\frac{1}{2} \mathrm{O}_{2} \longrightarrow \mathrm{AlO}_{2} \\
\mathrm{Al}_{(\mathrm{g})}+\mathrm{CO}_{2} \longrightarrow \mathrm{AlO}+\mathrm{CO} \\
2 \mathrm{AlO}+\mathrm{CO}_{2} \longrightarrow \mathrm{Al}_{2} \mathrm{O}_{3}+\mathrm{CO} \\
\mathrm{Al}(\mathrm{g})+\mathrm{H}_{2} \mathrm{O} \longrightarrow \mathrm{AlO}_{2}+\mathrm{H}_{2} \\
2 \mathrm{AlO}+\mathrm{H}_{2} \mathrm{O} \longrightarrow \mathrm{Al}_{2} \mathrm{O}_{3}+\mathrm{H}_{2}
\end{gathered}
$$

The designer selects a propellant type that is likely to give the required performance, cost, mechanical properties as well as the necessary storage stability and the best safety properties (non-toxic and smokeless).

\section{THEORETICAL PERFORMANCE STUDY}

The theoretical performance of the hybrid propellant combustion was studied and discussed for pure PE and PE with Al\%+gaseous oxygen using a standard thermochemical code ( $I_{\mathrm{sp}}$ code) [8]. It was assumed that there is no energy or mass transfer to the surroundings. In addition, gases are ideal and that the thermal and dynamic equilibrium between condensed products and the gaseous jet are maintained. The volume of the condensed phase is neglected relative to the gaseous volume. The chemical reaction rates are assumed fast with regards to the residence time in the nozzle. The used equations include chemical reactions, mass conservation, chemical equilibrium and energy conservation. The pressure equations are solved by an iterative technique, based on the Newton-Raphson method. 
The stoichometric ratio for $\mathrm{PE}$ with $\mathrm{GO}_{2}$ is 3.4 and performance characterizes $\left(\mathrm{I}_{\mathrm{sp}}, \mathrm{T}_{\mathrm{c}}\right.$, $\mathrm{C}^{*}, \mathrm{M}, \gamma$ ) are plotted for different mixture ratios as shown in Figures (3) through (6). It could be seen that, the performance parameters have maximum for $\mathrm{O} / \mathrm{F}=2.3$. Experimental work operating zone is done with oxidizer rich to safe the nozzle and measurement instrumentation from high combustion temperature.

\section{COMPUTER PROGRAM}

In this section, the metalized solid fuel $\dot{\mathrm{r}}_{\mathrm{fu}}$ and HRM performance parameters are introduced. Detail of the $\dot{r}_{\mathrm{fu}}$ model are introduced the model is applied on a small scale hybrid rocket motor (SSHRM) to predict the variation of different parameter with the operating time.

The ratio between the combustion chamber and the nozzle-exit pressures is an important parameter as it determines the expansion of the combustion gases. According to the thermo-chemical calculations [8] Figure (7), the value of the specific heat ratio $\gamma$ is approximately $1.20-1.32$ for all of the $\mathrm{PE}+\mathrm{Al} \%+\mathrm{GO}_{2}$ propellants. The critical pressure ratio across the exit nozzle required to maintain sonic flow at the throat is given by:

$$
\frac{P_{c}}{P_{a}}=\left(\frac{\gamma+1}{2}\right)^{\frac{\gamma}{\gamma-1}}
$$

For $\gamma=1.20-1.32$, the value of this ratio is over 1.77 , giving chamber operating pressure $\mathrm{P}_{\mathrm{c}}$ about 2 bar for standard conditions. The lowest experimental mean pressure ratio was 2 with a sinusoidal variation of 0.15 . Therefore, the observed behavior cannot be attributed to an unsteady choking and un-choking of the nozzle.

Once the $\dot{r}_{\mathrm{fu}}$ is known for each distance along the length of the fuel grain, the corresponding fuel consumption rates are summed to give the total fuel mass flow rate. For choosing the mixture ratio $\mathrm{O} / \mathrm{F}$ and the given $\mathrm{P}_{\mathrm{c}}$, the corresponding theoretical characteristic velocity $\mathrm{C}_{\text {th }}^{*}$ is obtained as:

$$
\mathrm{C}_{\mathrm{th}}^{*}=\frac{\sqrt{\mathrm{RT}_{\mathrm{c}}}}{\Gamma}
$$

where: $\Gamma=\sqrt{\gamma}\left(\frac{2}{\gamma+1}\right)^{\frac{\gamma+1}{2(\gamma-1)}}$

A new value of the pressure is calculated with the help of the experimental combustion efficiency $\eta_{c}$ as: 


$$
\mathrm{P}_{\mathrm{C}}=\frac{\mathrm{C}^{*} \dot{\mathrm{m}}_{\text {tot }}}{\eta_{\mathrm{c}} \mathrm{A}_{\mathrm{th}}}
$$

The value of the pressure is accepted when the iterations yield an error less than 0.05 bar. The corresponding value of $\dot{r}_{f u}$ is considered correct.

The $\mathrm{P}_{\mathrm{c}}$ varies during burning time due to variation of the total mass flow rate. Once the $\dot{r}_{\mathrm{fu}}$ is determined, the fuel flow rate and O/F are calculated as:

$$
\begin{gathered}
\dot{\mathrm{m}}_{\mathrm{fu}}(\text { new })=\sum_{\mathrm{x}=0}^{\mathrm{x}=\mathrm{L}_{\mathrm{fu}}} \rho_{\mathrm{fu}} \dot{\mathrm{r}}_{\mathrm{fu}} \pi d_{\mathrm{po}}(\mathrm{x}, \mathrm{t}) \Delta \mathrm{x} \\
\mathrm{O} / \mathrm{F}=\frac{\dot{\mathrm{m}}_{\mathrm{ox}}}{\dot{\mathrm{m}}_{\mathrm{fu}}}
\end{gathered}
$$

Having determined the $P_{c}$ and $\dot{r}_{f u}$. It is possible to estimate thrust $F$, specific impulse $I_{s p}$ and other performance parameters as shown in Figure (7) which describes block diagram of computer program.

The mathematical model for calculating the behavior and predicting hybrid $\dot{r}_{f u}$ is dependent on an understanding of both convection and radiation heat transfer phenomena.

The $\dot{r}_{f u}$ of HPS is more complex than of SPS. An understanding of hybrid $\dot{r}_{f u}$ is dependent upon an understanding of the interrelationships between the heat transfer phenomena and fuel grain geometry during burning time.

Hybrid $\dot{r}_{f u}$ modeling deals primarily with the transport of heat by convection and radiation from the diffusion flame zone (located in the turbulent boundary layer) to the solid fuel grain surface. For an unmetallized polymer, neglecting the radiation heat transfer is regarded as a reasonable approximation. This would considerably simplify the treatment.

\section{Metallized Fuel Grain Regression Rate}

In HRM, $\dot{r}_{f u}$ combustion gases containing large numbers of solid particles (aluminum powder), an important part of the energy absorbed by the fuel surface may be radiant heat. The dependence of $\dot{r}_{\mathrm{fu}}$ on convective heat transfer $\dot{Q}_{c}$ and radiative heat transfer $\dot{Q}_{r}$ may be given by [9]:

$$
\rho_{v} \dot{r}_{f u}=\rho_{f u}(1-k) \dot{r}_{f u}=\left(\frac{\dot{Q}_{c}}{h_{\text {veff }}}\right)\left[\left(\frac{\dot{Q}_{r}}{\dot{Q}_{c}}\right)+e^{-\frac{\dot{Q}_{r}}{\dot{Q}_{c}}}\right]
$$




$$
\begin{gathered}
\dot{\mathrm{Q}}_{\mathrm{c}}=0.036\left(\frac{\dot{\mathrm{m}}_{\mathrm{g}}}{\mathrm{A}_{\mathrm{po}}}\right)^{0.8}\left(\frac{\mathrm{x}}{\mu}\right)^{-0.2} \mathrm{~h}_{\mathrm{veff}} \beta^{0.23} \\
\dot{\mathrm{Q}}_{\mathrm{r}}=\alpha \varepsilon \mathrm{T}_{\mathrm{r}}^{4}\left(1-\mathrm{e}^{-\alpha \mathrm{N})}\right.
\end{gathered}
$$

where $\rho_{v}$ is the bulk density of volatile component of fuel grain, $K$ is the mass of fraction of non-volatile surface material, $\dot{m}_{g}$ is the total gas flow rate, $A_{p o}$ is the effective port area, $\alpha$ is the Empirical radiation coefficient, $\varepsilon$ is the emissivity of the fuel grain surface, $T_{r}$ is the effective radiation temperature and $N$ is the radiation parameter.

The $\dot{r}_{f u}$ described in equation (12), represents the coupling that occurs between convection and radiation heat transfer from a thin diffusion flame zone to the solid fuel grain surface, given by equations (13),(14). It depends upon the local $\mathrm{G}_{\text {tot }}$ and $P_{C}$.

The total gas flow $\dot{\mathrm{m}}_{\mathrm{g}}$ can be described at any point of the gaseous stream of the combustion products, $\dot{\mathrm{m}}_{\mathrm{g}}=\mathrm{f}(\mathrm{x})$, which is composed of the rate of head-end oxidizer flow plus the gas evolved from the surface minus the oxidizer consumed in the combustion. That can be describing by the following equations according to state of combustion [9]:

$$
\dot{\mathrm{m}}_{\mathrm{g}}=\dot{\mathrm{m}}_{\mathrm{o}}+\left(1-\frac{\mathrm{k} \zeta}{1-\mathrm{k}}\right) \int_{0}^{\mathrm{x}} \rho_{\mathrm{v}} \dot{\mathrm{r}} \mathrm{P} \mathrm{dx}
$$

where $\mathrm{K}_{1}$ is the mass fraction constant, volatile with particulate combustion products, $P$ is the internal perimeter of fuel grain.

If particles in the grain produce particulate combustion products:

$$
\dot{\mathrm{m}}_{\mathrm{g}}=\dot{\mathrm{m}}_{\mathrm{o}}+\frac{1}{1-\mathrm{k}} \int_{0}^{\mathrm{x}} \rho_{\mathrm{v}} \dot{\mathrm{r} P} \mathrm{dx}
$$

If particles in the grain produce only gaseous combustion products, and

$$
\dot{\mathrm{m}}_{\mathrm{g}}=\dot{\mathrm{m}}_{\mathrm{o}}+\left(1-\mathrm{k}_{1}-\mathrm{k}_{1} \zeta_{1}\right) \int_{0}^{\mathrm{x}} \rho_{\mathrm{v}} \dot{\mathrm{r}} \mathrm{P} \mathrm{dx}
$$

If a completely vaporizing, grain produces particulate combustion products. The mass of oxidizer consumed in producing the product particles is accounted for by $\zeta$ and $\zeta_{1}$.

$$
\dot{\mathrm{m}}_{\mathrm{g}}=\dot{\mathrm{m}}_{\mathrm{ox}}+\left(1-\mathrm{k}_{1}-\mathrm{k}_{1} \zeta_{1}\right) \int_{0}^{\mathrm{x}} \rho_{\mathrm{v}} \dot{\mathrm{r}}_{\mathrm{fu}} \mathrm{Pdx}
$$


This equation assumes that a completely vaporizing grain produces particulate combustion products. The factor $\zeta_{1}$ accounts for the mass of oxidizer consumed in producing these particles.

The local mixture ratio at the flame zone is known to be fuel rich, and is estimated as $3 / 4$ stochiometric mixture ratio [10]. It is considered independent of axial fuel grain length. The effective wall emissivity $\varepsilon=0.90$ as estimated by Muzzy [11].

\section{Chemical Parameters of Al Powder Additives}

There are several fundamental chemical parameters of the propellants, which are an inherent of the computer program.

The $1^{\text {st }}$ parameter, $\zeta$ mass of oxidizer consumed in producing particulate products per unit mass of non-vaporizing components in solid fuel, is introduced into the program in the evaluation of the gas flow. As metal particles are ejected into the main core and burn to their oxide, oxygen is consumed from the core flow. The vaporizing fuel particles are represented by $\zeta$ when the fuel contains Aluminum particles.

$$
2 \mathrm{Al}+\left(\frac{3}{2}\right) \mathrm{O}_{2} \rightarrow \mathrm{Al}_{2} \mathrm{O}_{3}
$$

$\zeta=\left(3 / 2 \mathrm{mw} \mathrm{O}_{2}\right) / 2 \mathrm{mwAl}=48 / 54=0.888$

The $2^{\text {nd }}$ parameter, $T_{r}$ represent the average temperature over the effective radiative zone. In a propellant which utilizes $\mathrm{Al}$ in a binder matrix and oxygen as the oxidizer, the value for $T_{r}$ is taken as 2/3 flame temperature. The flame temperature can be calculated from thermo-chemical code [8], the surface fuel grain temperature is assumed 600 to $800 \mathrm{~K}[10]$.

The $3^{\text {rd }}$ parameter, the effective combustion gases density $\rho_{g}$, specific heat ratio $\gamma$, and molecular weight $\mathrm{M}$ used for internal ballistics parameters evaluation. For a wide number of propellants, such as Al loaded fuel with oxygen gas as oxidizer $\gamma$ has a value of about 1.20 up to 1.32 .

\section{Case Study}

The $\dot{r}_{f u}$ software program has been applied to the case of a SSHRM with the following data: $\dot{\mathrm{m}}_{\mathrm{ox}}=9.3 \mathrm{gm} / \mathrm{s}, \mathrm{L}_{\mathrm{fu}}=80 \mathrm{~mm}, 2.5 \%$ Al additives, $\mathrm{d}_{\mathrm{po}}=5 \mathrm{~mm}$ and firing time $=5 \mathrm{~s}$. The typical program input includes: theoretical $\mathrm{C}^{*}$ data for $(\mathrm{PE}+2.5 \% \mathrm{Al})$ SF material with GO2 combustion, fuel and oxidizer characteristics, the basic motor dimensions, the basic performance constants and other input variables necessary for the computations. The typical main output indicates the transient values and boundary layer development along the fuel grain. Table (2) summarizes the average 
calculated performance parameters and the time variations of performance parameters are given in Figures (8) through (11).

Table (2) Summary the Average of Calculated Performance Parameters.

\begin{tabular}{|c|c|}
\hline Average Performance Parameter & Value \\
\hline Operating Pressure (bar) & 4.81 \\
\hline Regression Rate (mm/sec) & 0.5994 \\
\hline Mixture Ratio & 6.9 \\
\hline Fuel Port Radius & 5.32 \\
\hline
\end{tabular}

\section{EXPERIMENTAL WORK}

The direct goal of the experimental work is to check the validity of the $\dot{r}_{\text {fu }}$ mathematical model in case of metal powder additives and evaluating the performance of a designed SSHRM.

Factors of performance, safety, operability and cost need to be considered for any given application. Generally, the development, production and operation costs of the system play a major role in the selection of the propellant combination. It is initially chosen as a PE solid fuel for experimental and research due to availability, good casting and machinability, low cost, acceptable performance, the combustion products are environmentally safe $\left(\mathrm{H}_{2} \mathrm{O}\right.$ and $\left.\mathrm{CO}_{2}\right)$, long storage without any change of physical and chemical properties.

However, a main advantage of using AL powder with PE material in hybrid motor practical work is the low smoke and toxicity content in exhaust gases, and low price.

\section{Metalized Solid Grain Manufacturing}

Most of the propellant combinations are dangerous, toxic or expensive. The laboratory HRM model for researches, requires propellants that are readily available, reasonably safe, easy to handle and inexpensive. Based on experience, it is recommended to use gaseous oxygen as oxidizer and PE as solid fuel. They give good performance at PE and they show high safety.

Figure (12) shows the metalized solid fuel production tools, the injection moulding machine, the final product of $\mathrm{PE}$ or $\mathrm{PE}+\mathrm{AL}$ fuel grin and.PE fuel grain mold pattern, which is designed, produced and assembled at KADER factory, Cairo, Egypt. Table (3) shows the main characteristics of PE and AI materials.

Unfortunately, there are a number of inherent disadvantages during production. The mass of PE material, the plunger is compressing materials (injection pressure) and time of compressed mold (time of operation) are very sensitive to produce good product. Incomplete filling or low compression time would result in defected specimens, as figure (13). Figure (13a) shows irregular grain outer shape while figure (13b) shows the longitudinal sectional view with inner cavities. 


\section{Tested Hybrid Motor}

Figure (14) describes SSHRM oxidizer gas supply system. Normal industrial GO2 bottles with maximum pressure 100 bar are used. Pressure regulator has been used to control oxygen mass flow as shown in figure (14-a), as measured by a Rota-meter of maximum scale $15 \mathrm{gm} / \mathrm{s}$, located just upstream of hybrid motor as shown in figure (14-b).

The control solenoid valve in the supply line opened and closed from the control room by $220 \mathrm{~V}$ in Figure (14-c). Moreover, the solenoid valve and ignition spark are engaged from relay switch connected, to make sure the combustion chamber is fully developed of gaseous oxygen before ignition spark in case of pyrotechnic charge or by heat exchanger.

A copper tub of $6 \mathrm{~mm}$ outer diameter is used of the high-pressure line, and a tube from hard rubber material is used at the low-pressure line. For best sealing, Swagelok fittings are used as shows in figure (14-d).

The SSHRM system is operated from control room at atmospheric conditions $20 \pm 5$ ${ }^{\circ} \mathrm{C}$. The duration of the oxygen supply and ignition time can be adjusted from control room.

Table (3) The Main Characteristics of PE and Al Materials.

\begin{tabular}{|l|c|c|}
\hline \multicolumn{1}{|c|}{ Parameters } & PE & Al \\
\hline Molecular formula & $(\mathrm{C} 2 \mathrm{H} 4) \mathrm{n}$ & $\mathrm{Al}$ \\
\hline Molecular weight(Kg/K mol) & 28.05 & 26.98 \\
\hline Density(Kg/m3) & 940 & 2700 \\
\hline Melting point(k) & 450 & 660 \\
\hline Heat of combustion(MJ/Kg) & 46.4 & 10.71 \\
\hline Standard heat of formation(KJ/mol) & -58.6 & 0 \\
\hline
\end{tabular}

\section{Static Firing Tests}

The SSHRM should pass a series of cold tests (at least 30 bar for 15 minutes without leakage or failure).to minimize the risk of damage during firing. Silicon materials, which are good for oxidizer environments, are employed to ensure a static force seal for the SSHRM and fuel grain support interface with $3 \mathrm{~mm}$ thick asbestos or Teflon gasket in both ends for heat protection.

The hot testing of the SSHRM is accomplished, through large number of experiments to investigate $\dot{r}_{\mathrm{fu}}$ of PE with different Al powder percentages $(2.5,5$, $7.5,10,12.5$, and $15 \%)$.

The system allows the measuring of pressures at the feed line, GO2 tank, prechamber; flow rates of GO2; and temperature in the pre-chamber during the test run. In addition, other variables are measured before and after a test run, ambient temperature, and nozzle throat diameter, mass of the fuel grain using digital balance. The system is adjusted to read 60 points per one second. During test, 2 channels 
are used: one channel for pressure and the other channel for temperature. Recorded data of pressure and temperature are shown in Figure (15).

\section{RESULTS AND DISCUSSIONS}

Over 50 test runs have been performed. Variations of Al powder percent, port diameter, fuel grain length and oxidizer flow rate are considered. Samples results from static firing tests on SSHRM are given in Table (4) and Figure (15).

In order to check the validity of the developed mathematical model, it is useful to predict the following important parameters for a known rocket motor variation of $\mathrm{P}_{\mathrm{c}}$ and $\dot{\mathrm{r}}_{\mathrm{fu}}$.

Table (4) Static Firing Results of Hybrid Motor.

\begin{tabular}{|c|c|}
\hline $\begin{array}{l}\text { Regulator pressure }=10 \text { bar } \\
\text { Throat diameter }=6 \mathrm{~mm} \\
\text { Measured oxidizer mass flow rate }=9.3 \mathrm{gm} / \mathrm{s} \\
\text { Fuel grain length }=80 \mathrm{~mm} \\
\text { Final port diameter }=10.9 \mathrm{~mm}\end{array}$ & $\begin{array}{l}\text { Maximum Temperature }=1054.1^{\circ} \mathrm{C} \\
\text { Burning time }=4.13 \mathrm{~s} \\
\text { Fuel mass consumed }=5.8 \mathrm{gm} \\
\text { Initial diameter }=5 \mathrm{~mm}\end{array}$ \\
\hline \multicolumn{2}{|l|}{ Calculated data } \\
\hline $\begin{array}{l}\text { Ignition time }=0.93 \mathrm{~s} \\
\text { Average pressure }=5.29 \text { bar } \\
\text { Regression rate }(\Delta \text { mass })=0.7143 \mathrm{~mm} / \mathrm{s} \\
\text { Experimental characteristic velocity }=1397.3 \mathrm{~m} / \mathrm{s} \\
\text { Combustion efficiency }=93.7 \%\end{array}$ & $\begin{array}{l}\text { Fuel mass flow rate }=1.404 \mathrm{gm} / \mathrm{s} \\
\text { Mean mixture ratio }=6.62 \\
\text { Regression rate }(\Delta \text { diameter })=0.7143 \mathrm{~mm} / \mathrm{s} \\
\text { Theoretical characteristic velocity }=1490.8 \mathrm{~m} / \mathrm{s}\end{array}$ \\
\hline
\end{tabular}

The measured experimental data are compared with results obtained from theoretical computation. The comparison shows good agreement, as seen in Table (5), which proves the validity of the developed program, since the maximum error noticed was generally less than $10 \%$.

Table (5) Comparison of Computer and Measured Values.

\begin{tabular}{|l|c|c|c|}
\hline Parameter & Program & Measurement & Average Error \% \\
\hline Chamber pressure, (bar) & $5.2-4.39$ & 4.31 & 9.5 \\
Regression rate, $(\mathrm{mm} / \mathrm{s})$ & $1.13-0.37$ & 0.71 & 5.6 \\
Mixture ratio & $5.05-8.15$ & 6.62 & 0.3 \\
\hline
\end{tabular}

In Figure (16), the $P_{c}$ with time obtained from computer program is compared with the test results. It can be seen that during the first $2 \mathrm{~s}$, the theoretical calculated values are somewhat greater than the values from test. It is observed that the maximum error of about $19.6 \%$ of chamber pressure occurs at the beginning of the burning time, and the error drops to $4.2 \%$ at the end of burning. This can be explained by:

1) The fuel grain channel machining tolerance.

2) Neglecting fuel regression during the ignition period using heat exchanger (hot air).

3) The large number of assumed input variables, being too difficult to be accurately estimated. 


\section{CONCLUSION}

The objective of the present work is to study the metalized combustion of the HRM through enhancement of hybrid fuel regression. A SSHRM has been designed, manufactured and used with different initial port diameter of fuel grain and different Al powder percent $(2.5,5.0,7.5,10.0,12.5$, and $15.0 \%)$. The used propellant was $\mathrm{PE}$ or $\mathrm{PE}+\mathrm{AL}$ in the form of a tubular grain as fuel and gas oxygen as oxidizer, both selected for reasons of availability and safety.

The experiments took place for chamber pressure up to 10 bar, firing duration about $5 \mathrm{sec}$, fuel grain length about $75 \mathrm{~mm}$, oxidizer mass flow rate up to $10 \mathrm{gm} / \mathrm{s}$.

A mathematical model has been implemented to solve metalized solid fuel regression rate for HRM and metalized combustion phenomena in hybrid system was investigated.

Based on this model, a computer code has been implemented to predict HRM parameters. The program was validated through the comparison of predicted and measured pressure histories and performance parameters for a SSHRM, the maximum error noticed was generally less than $10 \%$.

During the experimental work has lead to the following conclusions:

- PE is chosen as a solid fuel for performing the experimental work, thanks to its good machinability, low cost, acceptable performance, availability in many forms and environmentally safe combustion products.

- The selection of oxygen as oxidizer is based on quality of handling, storability, transportability, ignition, toxicity, and other parameters.

- Choice Al powder as energetic material is based on its thermal properties, ease of processing, and relatively low cost.

- Combustion efficiency reaches about $93 \%$ with addition of $2.5 \% \mathrm{Al} \%$.

- Reduced emissions of product gases (soot, unburned hydrocarbons) with addition Al powder.

- Checked the validity of the regression rate mathematical model in case of metal powder additives and evaluating the performance of a designed SSHRM.

- Regression rate of hybrid fuel grain was enhanced by addition of Al powder. Adding up to $7.5 \%$ gives the best performance as regression rate increases by $90 \%$ and chamber pressure increases by $40 \%$ compared to basic configuration ( $0 \% \mathrm{Al})$.

\section{REFERENCES}

[1] Marxman, G. A.,Wooldrige, C. E., and Muzzy, R. J., "Fundamentals of Hybrid Boundary-Layer Combustion". Heterogeneous Combustion, edited by H.G. Wolfhord, I. Glassman, and L. Green, J.,Vol.15, Progress in Astronautics and Aeronautics, Academic Press, New York, 1964.

[2] Humble, R., Henry, Gary, N.and Larson, Wiley, J., "Propulsion System Analysis and Design," United States Air Force Academy, 1995.

[3] Winfried M.S, and Schmucker R.H, "Development of A Small Hybrid Rocket Motor" Institute of astronauts, Technical University Munchen, September 1971. 
[4] Winfried M.S, and Schmucker R.H, "Influence of Different Parameter on the Starting Behavior Of Hybrid Engines" Institute of astronauts, Technical University Munchen, 14 April, 1974.

[5] Tuzinsk, W.A.“Hybrid Rocket” Institute of astronauts, Technical University Munchen,14 April 1970.

[6] Abel, T.M, Boardman, T.A, Poter, L.G, and Brasfield, F.W, "An ultrasonic Fuel Regression Rate Measurment Technique for mixture Ratio Control of a Hybrid Motor" AIAA 95-3081, July, 1995.

[7] Wernimont, E, and Meyer, S, "Hydrogen Peroxide Hybrid Rocket Engine Performance Investigation" AIAA 94-3147, June 27-29, 1994.

[8] Selph, C, "Computer Program For calculation of Complex Chemical Equilibrium Composition" NASA SP-273, United States Air force Academy, version, July 1994.

[9] Wooldrige, C.E, and muzzy, R.J, "Internal Ballistic Considerations in Hybrid Rocket Design" j.Spacecraft Vol.4, No.2, Feb.1967.

[10] David, W, Netzer, "Hybrid Rocket Internal Ballistics" Naval Postgraduate School, Monterey, January 1972.

[11] Muzzy. R.J, "Schlieren and Shadowgraph Studies of hybrid Boundary layer Combustion" AIAA journal, Vol. 1,No.9, pp.2159-2160,1963.

\section{Figures:}

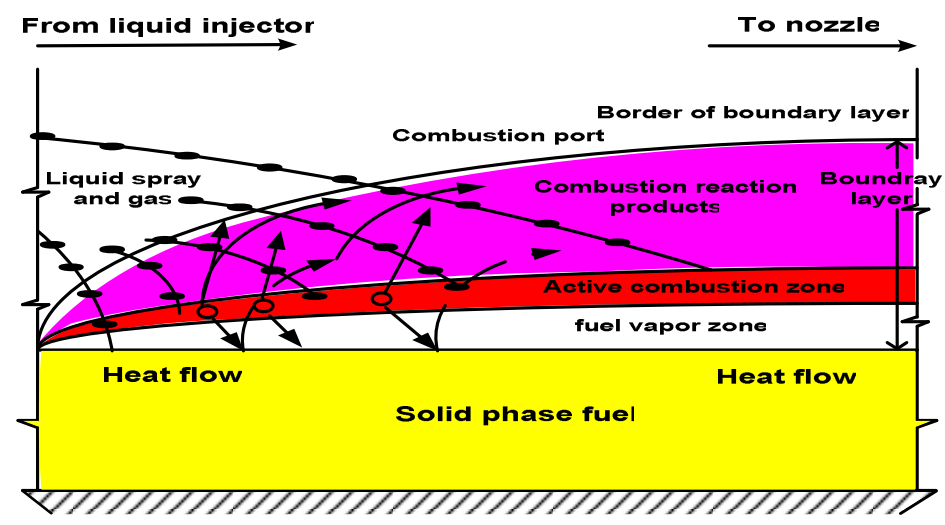

Fig. (1) Model of Hybrid Combustion Process.



Fig. (2) Al Particle Combustion Mechanism. 


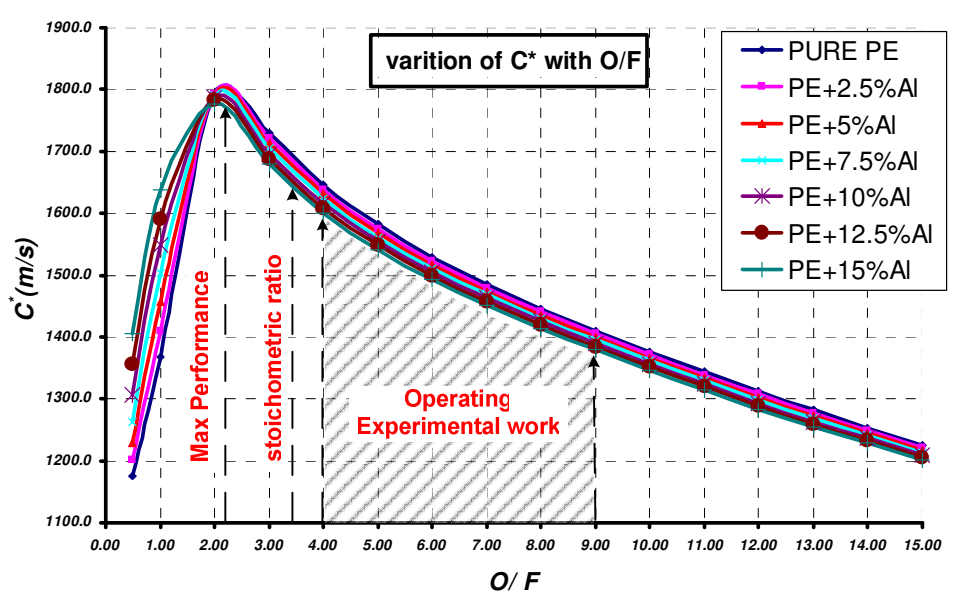

Fig. (3) $\mathrm{PE}+\mathrm{Al}+\mathrm{O}_{2}$ Propellant $\mathrm{C}^{*}$ Versus $\mathrm{O} / \mathrm{F}$.

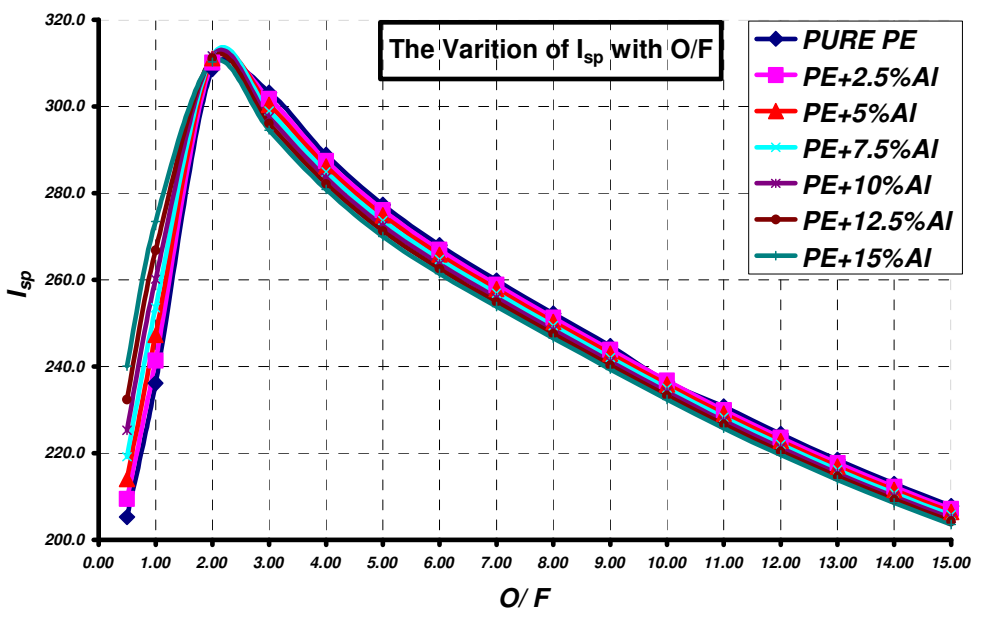

Fig. (4) $\mathrm{PE}+\mathrm{Al}+\mathrm{O}_{2}$ Propellant Isp Versus O/F.

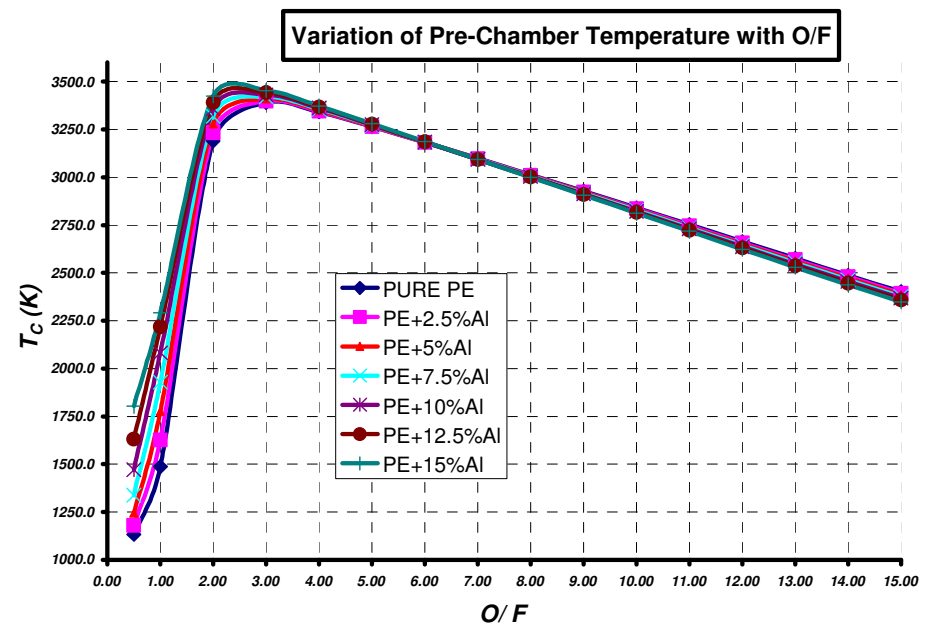

Fig. (5) $\mathrm{PE}+\mathrm{Al}+\mathrm{O}_{2}$ Propellant $\mathrm{T}_{\mathrm{c}}$ Versus $\mathrm{O} / \mathrm{F}$. 


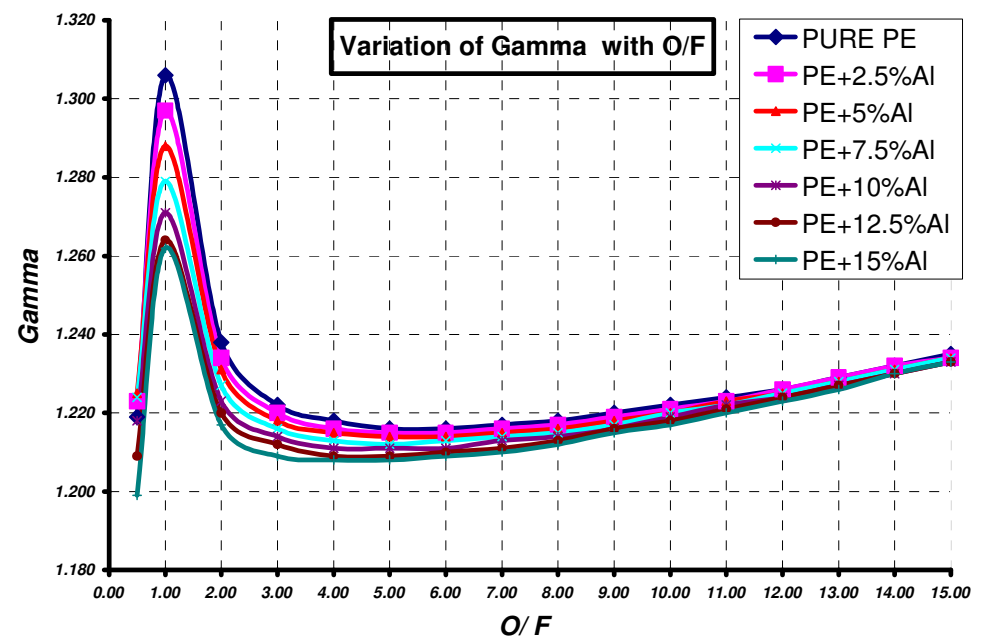

Fig. (6) $\mathrm{PE}+\mathrm{Al}+\mathrm{O}_{2}$ Propellant Specific Heat Ratio versus O/F.



Fig. (7) Block Diagram of Computer Program. 


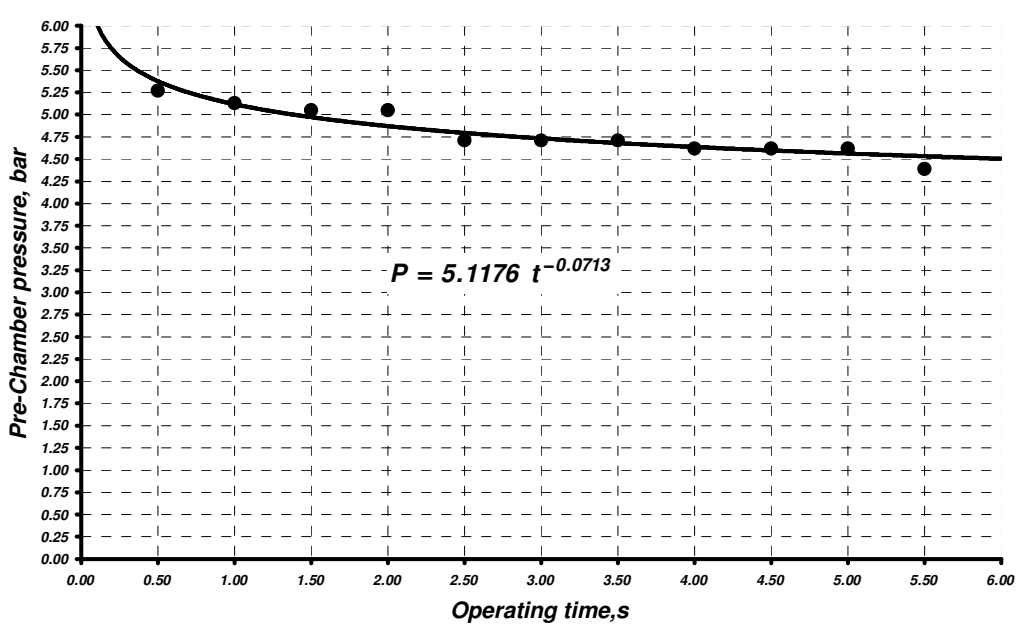

Fig. (8) Calculated $P_{c}$ with Operating Time.

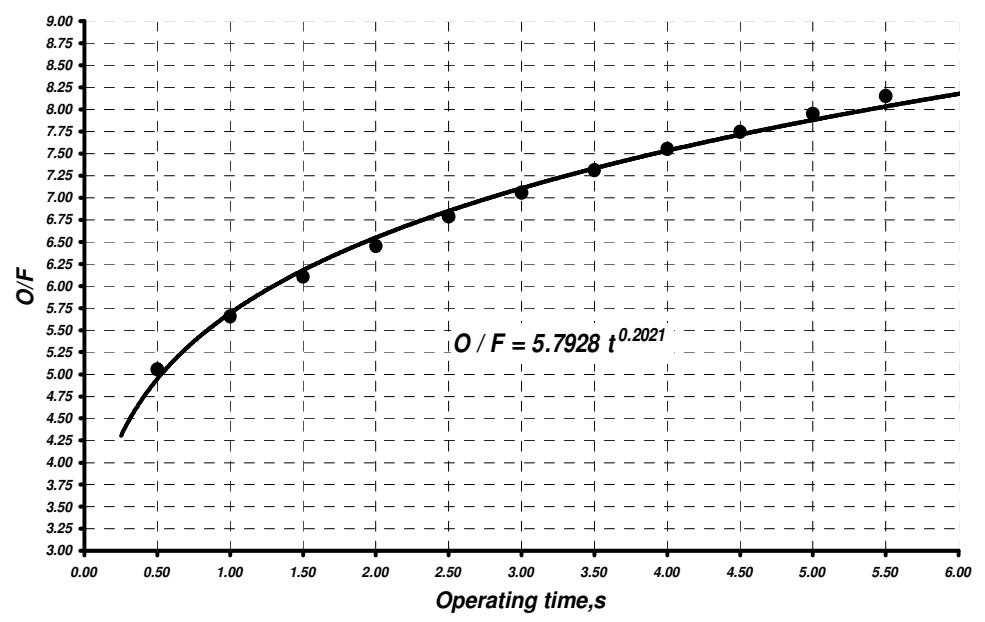

Fig. (9) Calculated Average O/F with Operating Time.

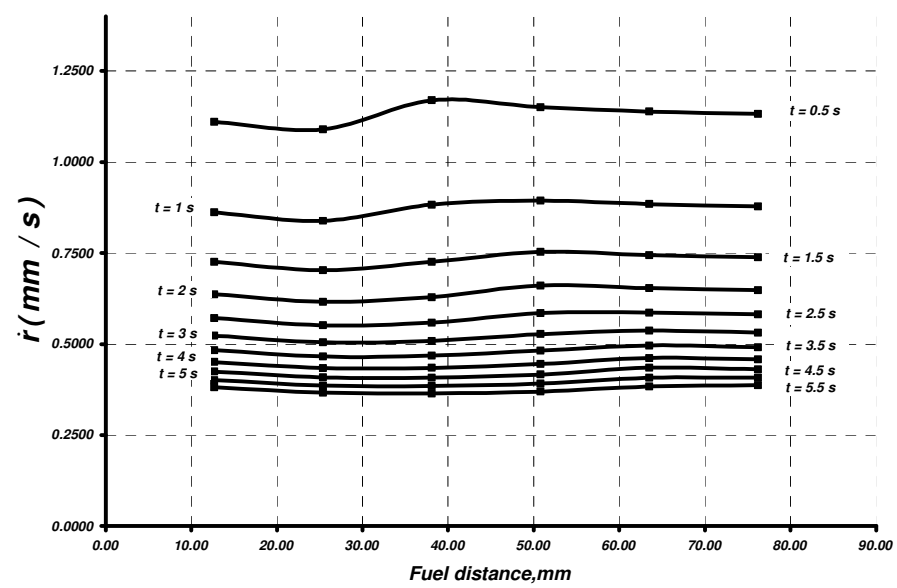

Fig. (10) Variation of $\dot{r}_{\text {fu }}$ Along FG During Operating Time. 


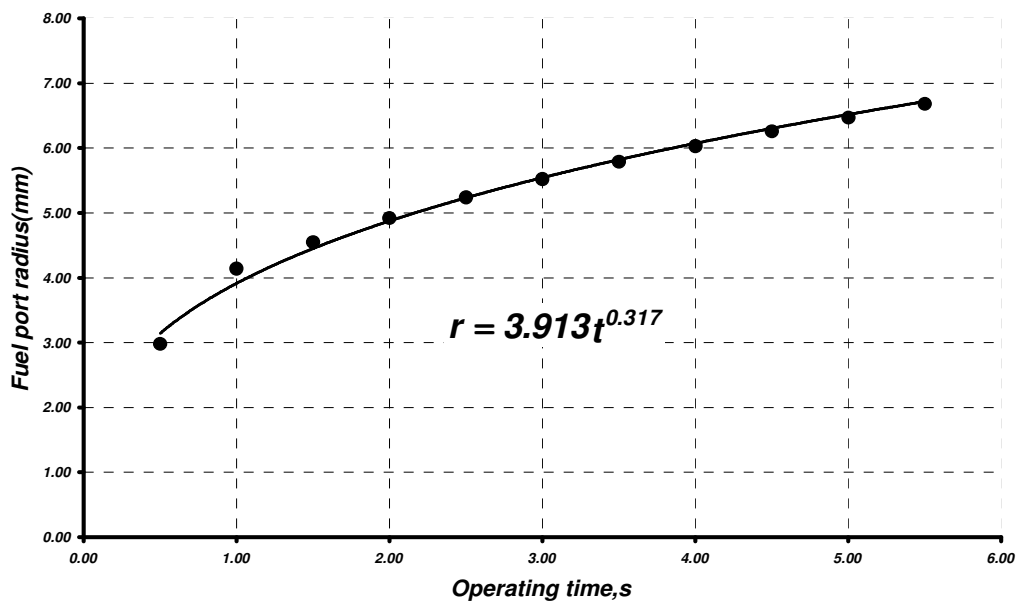

Fig. (11) Variation Of Fuel Port Radius Along FG during Operating Time.
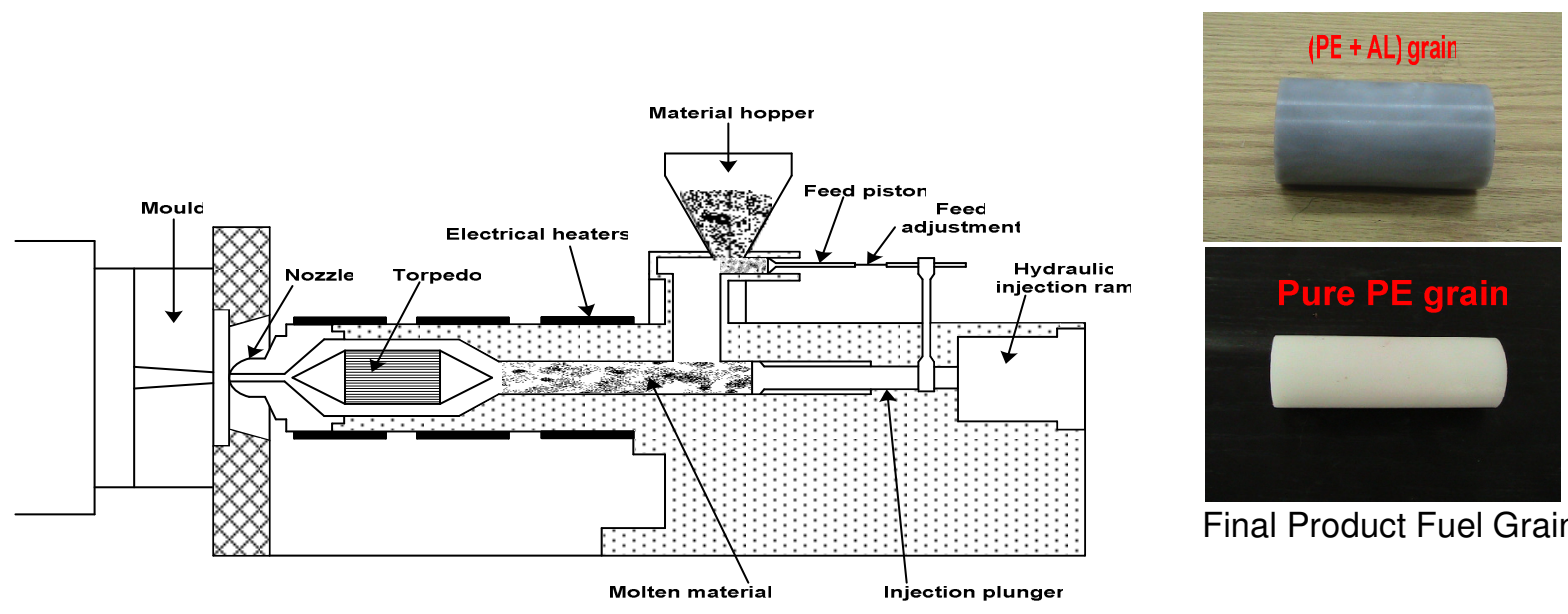

Final Product Fuel Grain

Plunger Type Injection Moulding Machine

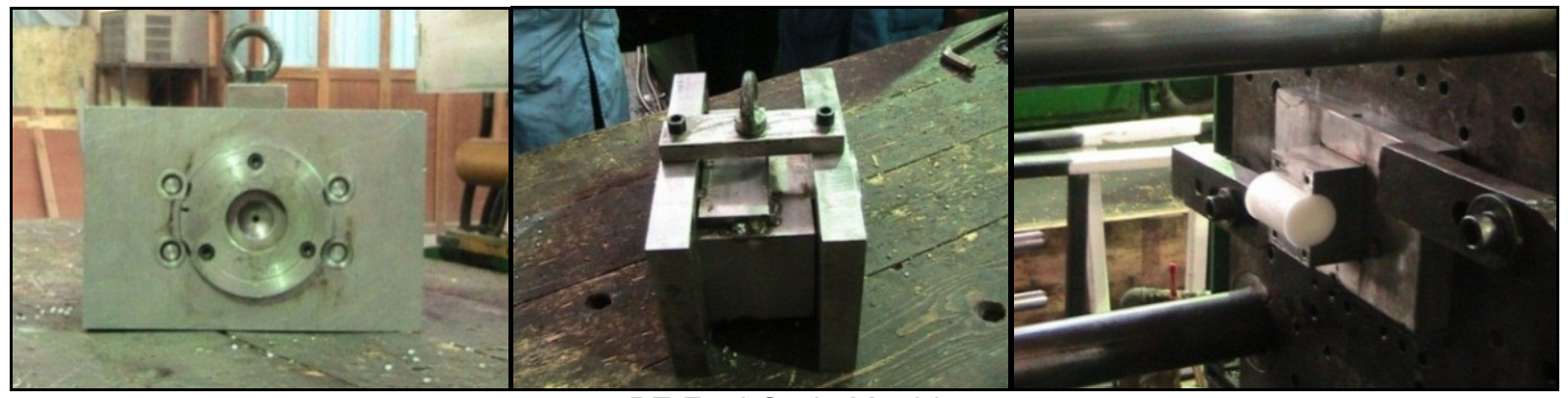

PE Fuel Grain Mould

Fig. (12) Fuel Grain Production process.

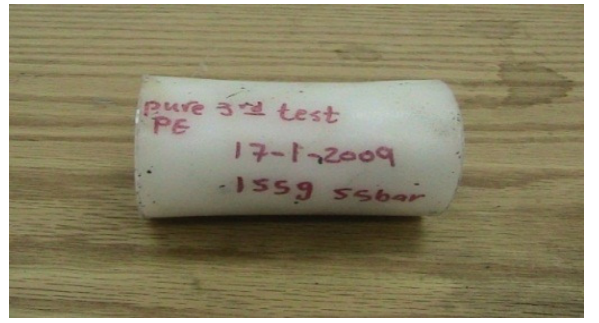

(a)

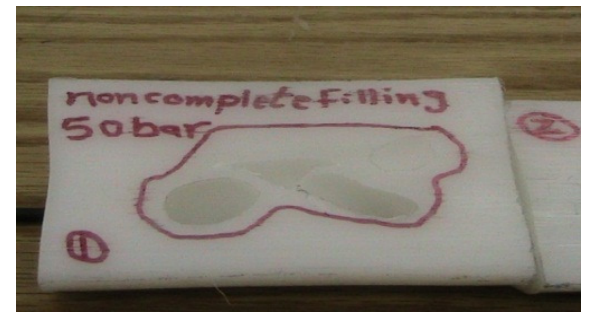

(b)

Fig. (13) Rejected Detected Specimens. 


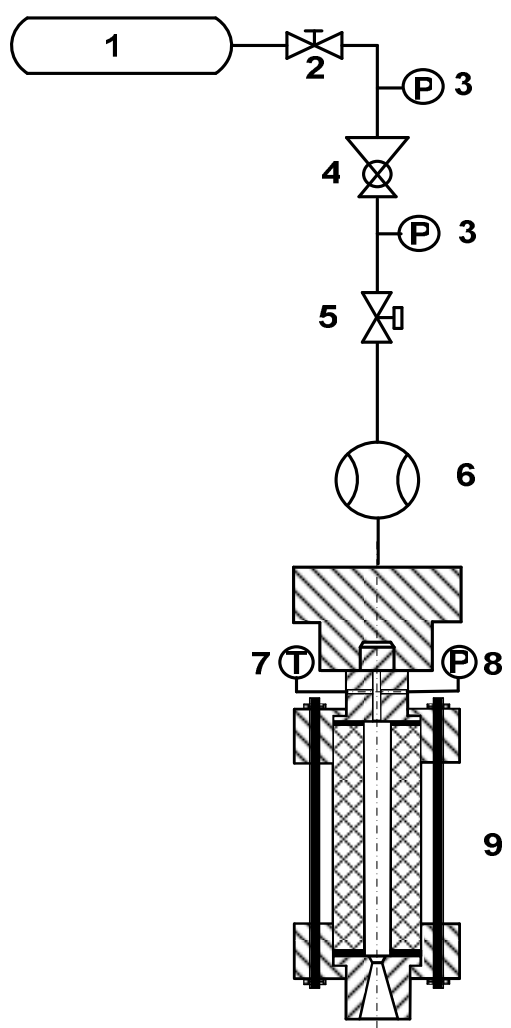

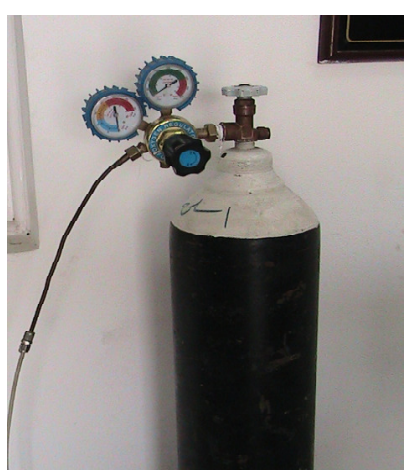

a) Pressure regulator (1)



b) Rota-meter (6).

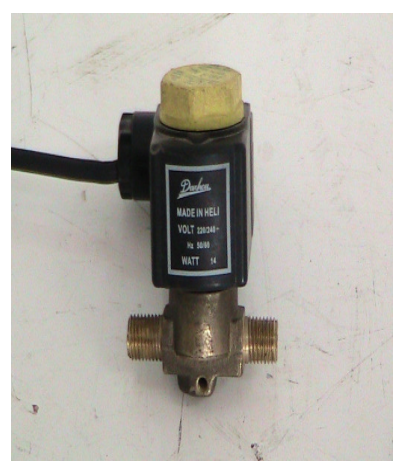

c) On-off valve (5) (Solenoid type)

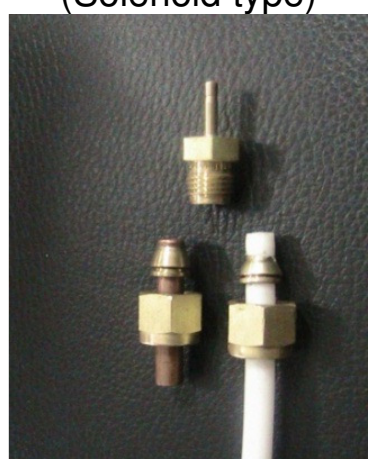

(d) Swagelok Fittings.

1-Oxidizer Tank, 2- Needle Valve, 3- Pressure Gage, 4- Pressure Regulator, 5- On-Off Valve, 6- Rota-Meter, 7- K-Type Thermocouple, 8- Pressure Transducer, 9- Hybrid Rocket Motor

Fig. (14) SSHRM Feeding System.

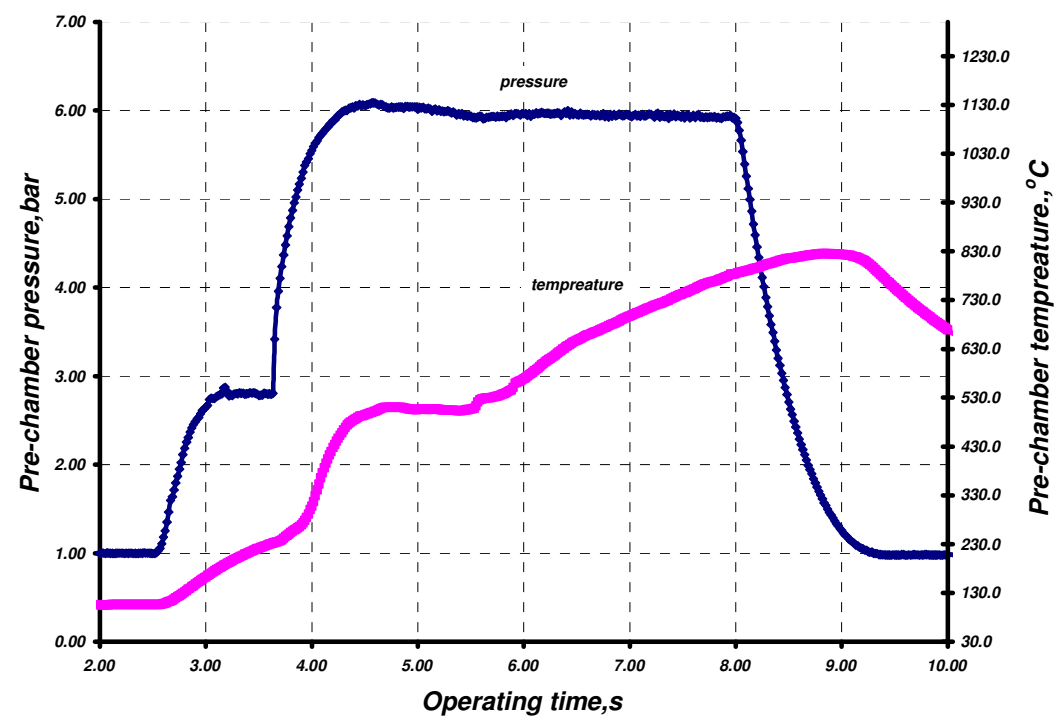

Fig. (15) Experimental pre-chamber pressure and Temperature with Operating Time. 


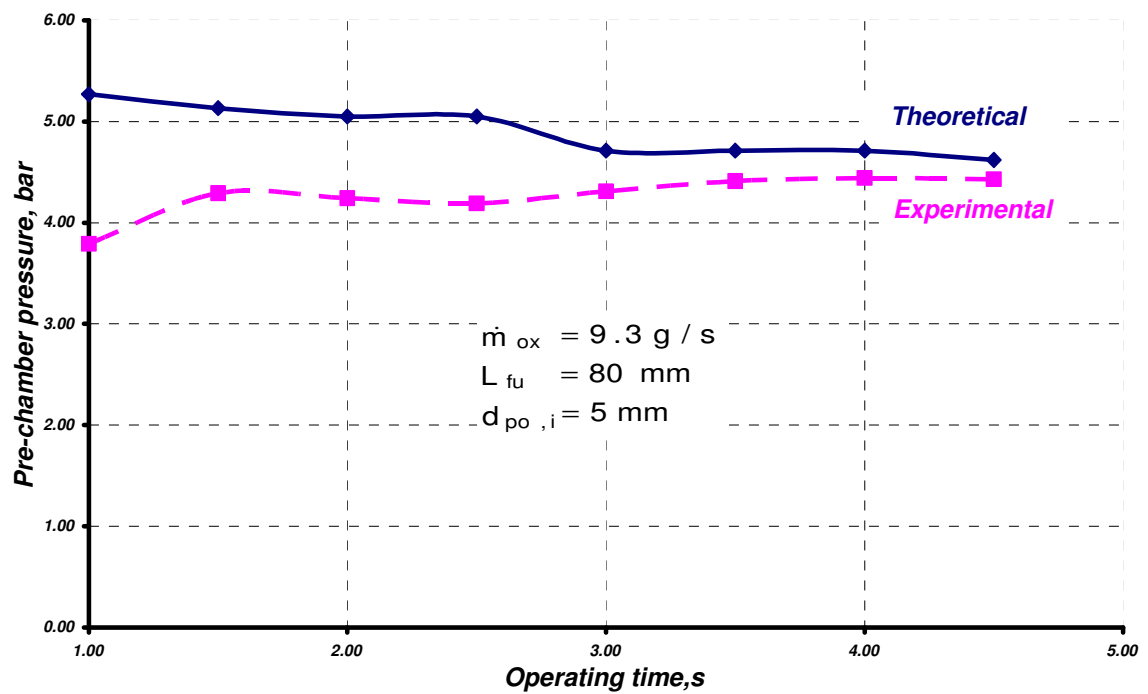

Fig. (16) Experimental and Theoretical Chamber Pressure. 